This is the post print version of the article, which has been published in Journal of electrocardiology. 2018, 51 (6), 939-940.https://doi.org/10.1016/j.jelectrocard.2018.07.020.

\title{
Severe hypercalcemia from multiple myeloma as an acquired cause of short QT
}

Yingwei Liu, MD; Andrés Ricardo Pérez-Riera, MD PhD²; Raimundo Barbosa-Barros, $\mathrm{MD}^{3}$;

Rodrigo Daminello-Raimundo², PhD; Luiz Carlos de Abreu, $\mathrm{PhD}^{2}$; Kjell Nikus, MD;

Adrian Baranchuk, MD¹.

1. Division of Cardiology, Kingston Health Science Center, Queen's University, Kingston, Ontario, Canada.

2. ABC School of Medicine, Santo André, Brazil.

3. Messejana Hospital Dr. Carlos Alberto Studart Gomes, Fortaleza, Brazil.

4. University of Tampere, Tampere, Finland.

Running Title: Multiple myeloma \& short QT

Key Words: Hypercalcemia, Short QT, Sudden cardiac death, Ventricular tachycardia,

Ventricular fibrillation

Financial support: None. The authors have no competing interests to declare.

\section{Address for Correspondence}

Adrian Baranchuk, MD FACC FRCPC FCCS

Professor of Medicine

Queen's University

FAPC, 3rd floor 76 Stuart Street

Kingston, Ontario, K7L2V7

Telephone: 613-549-6666 x3377

Fax: 613-548-1387

E-Mail: barancha@kgh.kari.net 


\section{Abstract}

An otherwise healthy 64-year-old man with recently diagnosed multiple myeloma was admitted to hospital with hypercalcemia and renal failure. Despite his electrocardiogram showing short QT/QTc intervals, he was admitted without cardiac monitoring. He died suddenly a few hours later, likely from a fatal arrhythmia. This case illustrates that pronounced QT shortening from hypercalcemia is an underappreciated malignant finding that can portend a significant risk for arrhythmia and sudden cardiac death. In addition, we also discuss the causes of hypercalcemia associated short QT/QTc intervals and its ECG features. 


\section{Introduction}

Although hypocalcaemia is a well-recognised cause of QT prolongation via prolongation of the plateau phase of the cardiac action potential, there is much less knowledge about hypercalcemia causing short QT. We present an unusual case of hypercalcemia causing short QT.

\section{Case Presentation}

An otherwise healthy 64-year-old man with recently diagnosed multiple myeloma was admitted to hospital with confusion, pain over his right fifth rib, and hyperreflexia. He was not known to have any structural heart disease or family history of syncope or sudden cardiac death. Investigations were notable for hypercalcemia and renal failure: Na 161 mEq/L (normal 135$145 \mathrm{mEq} / \mathrm{L}$ ), K $4.9 \mathrm{mEq} / \mathrm{L}$ (normal 3.5-5.0 mEq/L), creatinine 292 umol/L (normal 60-110 umol/L), Ca 4.89 mmol/L (normal 2.2-2.7 mmol/L), albumin 40 g/L (normal 35-55 g/L), CKMB $49.74 \mathrm{ng} / \mathrm{mL}$ (normal $\leq 7.7 \mathrm{ng} / \mathrm{mL}$ ), and troponin 0.069 (normal <0.04). His electrocardiogram showed extremely short QT/QTc intervals of 300 ms measured manually using the tangent method at a heart rate of 60 beats per minute (Figure 1). His chest X-ray demonstrated multiple lytic lesions. The remainder of his investigations were unremarkable. He was admitted to a ward bed without cardiac monitoring and initiated on intravenous fluids. He died suddenly a few hours later, unwitnessed.

\section{Discussion}

Some "take-home" messages can be derived from this tragic case. Whereas there have been several reports of hypercalcemia-induced ventricular tachycardia in patients with primary hyperparathyroidism ${ }^{1}$, this has never previously been described before with multiple myeloma. Multiple myeloma is a clonal neoplasm of plasma cells and the second most common adult hematologic malignancy. It causes hypercalcemia by secreting osteoclast activating factor, such as tumor necrosis factor-beta, interleukin-6, and receptor activator of nuclear factor kappa B ligand, which lead to bone resorption and release of calcium into the extracellular fluid. 
Hypercalcemia is a frequent acquired cause of QT shortening, which is postulated to be due to a shortening of phase 2 of the action potential secondary to a decrease in $\mathrm{Ca}^{2+}$ current and increase in calcium-activated $\mathrm{Cl}^{-}$current ${ }^{2}$. On the electrocardiogram, this translates into a shortening of the QT interval, primarily through shortening or absence of the ST segment within the QT interval. This in turns leads to an abbreviated ventricular refractory period, which is believed to predispose individuals to ventricular arrhythmias, in particular ventricular fibrillation and sudden cardiac death. ${ }^{3}$ Although there is an overlap between normal and pathologically short QT, like long QT, the arrhythmic risk of short QT rises exponentially with more extreme values. ${ }^{3}$ Thereby in our patient, it is plausible that the extreme hypercalcemia led to a pathologically short refractory period which increased the patient's vulnerability to a fatal arrhythmia and ultimately led to his sudden death overnight. In addition to short QT, several other ECG findings - some of which were also present in our patient - have been reported with hypercalcemia and are listed in Table 1. Apart from multiple myeloma, causes of hypercalcemia include other malignancies, primary and tertiary hyperparathyroidism, hypercalcemia of granulomatous disease, acute and chronic renal failure and medications such as thiazide diuretics, lithium, and vitamin D.

\section{Conclusion}

Pronounced QT interval shortening with shortening or absence of the ST segment is an underappreciated malignant finding that can portend a significant risk for arrhythmia and sudden cardiac death. Reports on multiple myeloma causing hypercalcemia-associated short QT have not been frequently published before. A change in our clinical practice regarding short QT should be considered. Monitoring patients vigilantly while investigating and reversing potential causes is paramount. 


\section{References}

1. Curione, M., Letizia, C., Amato, S., Di Bona, S., Di Fazio, F., Minisola, S., . . . D'Erasmo, E. (2007). Increased risk of cardiac death in primary hyperparathyroidism: what is a role of electrical instability? International Journal of Cardiology, 121(2):200-2. doi:10.1016/j.ijcard.2006.08.072

2. Bjerregaard, P., Nallapaneni, H., \& Gussak, I. (2010). Short QT interval in clinical practice. Journal of Electrocardiology, 43(5):390-5. doi:10.1016/j.jelectrocard.2010.06.004

3. Tse, G., Chan, Y.W.F,, Keung, W., \& Yana, B.P. (2017). Electrophysiological mechanisms of long and short QT syndromes. International Journal of Cardiology. Heart \& Vasculature, 14:8-13. doi: 10.1016/j.ijcha.2016.11.006

4. Shah, A.P., Lopez, A., Wachsner, R.Y., Meymandi, S.K., El-Bialy, A.K., \& Ichiuji, A.M. (2004). Sinus node dysfunction secondary to hyperparathyroidism. Journal of cardiovascular pharmacology and therapeutics, 9(2):145-147.

5. Durant, E., \& Singh, A. (2017). ST elevation due to hypercalcemia. The American journal of emergency medicine, 35(7):1033 e1033-1033 e1036. doi: 10.1016/j.ajem.2017.02.005.

6. Otero, J., \& Lenihan, D.J. (2000). The "normothermic" Osborn wave induced by severe hypercalcemia. Texas Heart Institute journal, 27(3):316-317.

7. Douglas, P.S., Carmichael, K.A., \& Palevsky, P.M. 1984. Extreme hypercalcemia and electrocardiographic changes. American Journal of Cardiology, 54(6):674-675. doi:10.1016/0002-9149(84)90274-1.

8. Saikawa, T., Tsumabuki, S., Nakagawa, M., Takakura, T., Tamura, M., Maeda, T., . . . Ito, M. (1988). QT intervals as an index of high serum calcium in hypercalcemia. Clinical cardiology, 11(2):75-78. doi:10.1002/clc.4960110205. 


\section{Legend}

Figure 1: ECG analysis: Sinus rhythm, HR 60 bpm, J-point elevation in V4, V5, I, and aVL, almost non-existent ST segment, extremely short QT/QTc (300 ms).

Table 1: ECG characteristic of hypercalcemia (potentially sensitive, but not specific) 


\section{Figure 1}

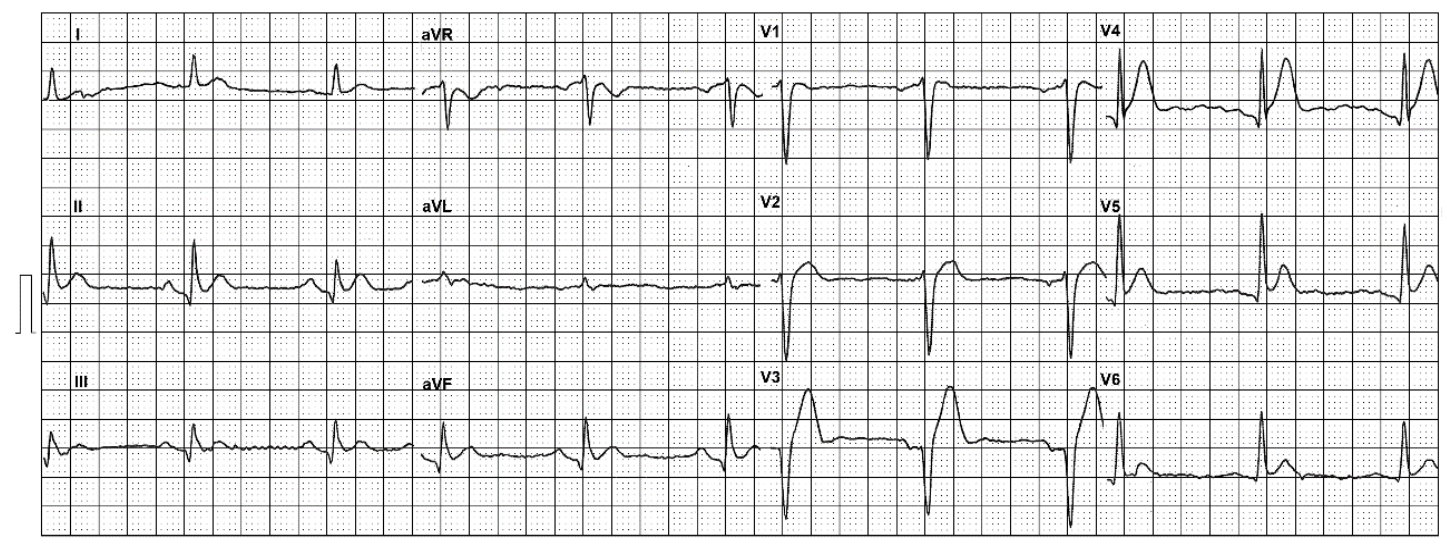

\section{Table 1}

\begin{tabular}{|c|c|}
\hline \multicolumn{2}{|c|}{ ECG characteristic of hypercalcemia } \\
\hline $\begin{array}{l}\text { Sinus } \\
\text { Rate }\end{array}$ & Symptomatic sinus node dysfunction is occasionally observed. ${ }^{4}$ \\
\hline $\begin{array}{l}\text { PR } \\
\text { interval }\end{array}$ & At very high ionized serum calcium levels, there can be slight PR prolongation. ${ }^{6}$ \\
\hline $\begin{array}{l}\text { ST } \\
\text { segment }\end{array}$ & $\begin{array}{l}\text { The ST segment is usually absent or almost absent, but if it is present, it can be depressed or } \\
\text { elevated mimicking acute myocardial infarction. }{ }^{5} \text { Prominent J point level elevation has been } \\
\text { noted and termed "normothermic" Osborn wave. }{ }^{6}\end{array}$ \\
\hline T wave & $\begin{array}{l}\text { The T wave can become flattened or inverted, biphasic, or notched with a marked decrease in } \\
\text { amplitude. }\end{array}$ \\
\hline QT & $\begin{array}{l}\text { The QT interval is often shortened. The corrected QT intervals (QTc) can be used as } \\
\text { indicators of clinical hypercalcemia. }\end{array}$ \\
\hline
\end{tabular}

